\title{
Guest editorial: advances in immunotherapy for hematological malignancies
}

\author{
Norimitsu Kadowaki ${ }^{1}$
}

Received: 5 February 2018 / Accepted: 5 February 2018 / Published online: 9 February 2018

(c) The Japanese Society of Hematology 2018

Tumor immunotherapy has come of age. Recent advances have been enabled by a rapidly growing body of knowledge on basic immunology and new technologies, culminating in the clinical deployment of two breakthrough modalities, engineered T cell therapy and immune checkpoint blockade.

Hematological malignancies are derived from immune cells, and are thus expected to have many chances to interact with normal immune cells. This provides unique opportunities for immunotherapy. For example, leukemia cells are highly accessible to infused lymphocytes, in contrast to solid cancers where interstitial tissues in tumor sites prevent access. Lymphoma usually has less interstitium than solid cancers, and thus also provides considerable access to immune cells. These features of hematological malignancies are among the key factors by which adoptive transfer of engineered T cells has remarkable effects on B cell leukemia, lymphoma, and multiple myeloma.

Blockade of PD-L1/PD-1 interaction has brought about another advance in immunotherapy for hematological malignancies. The clinical outcomes of anti-PD-1 monoclonal antibodies on Hodgkin's lymphoma are particularly impressive $[1,2]$. The tumor microenvironment of lymphoid malignancies often includes a substantial number of reactive $\mathrm{T}$ cells and macrophages, which may have immunosuppressive functions. Importantly, it has been reported that the immune microenvironment in lymphoma tissues strongly influences prognosis $[3,4]$. Thus, redirecting the immunosuppressive microenvironment of lymphoid malignancies to an immunefavorable one may promote the immunological elimination of tumor cells.

Norimitsu Kadowaki

kado@med.kagawa-u.ac.jp

1 Division of Hematology, Rheumatology and Respiratory Medicine, Department of Internal Medicine, Faculty of Medicine, Kagawa University, 1750-1 Ikenobe, Miki-cho, Kita-gun, Kagawa 761-0793, Japan
In this issue, Dr. Hiroshi Kawamoto presents promising data about the next generation of adoptive $\mathrm{T}$ cell therapy. Currently, engineered $\mathrm{T}$ cells are manufactured from the patients' own T cells. This method presents several challenges. First, T cells may be exhausted during expansion culture. Second, T cells prepared from different patients may not be of uniform quality. Third, it is labor intensive and costly to prepare $\mathrm{T}$ cells from each patient individually. Dr. Kawamoto proposes the use of induced pluripotent stem cell (iPSC)-derived "off-the-shelf" antigen-specific T cells, which would potentially overcome most of the drawbacks of the current autologous approach.

Dr. Rohtesh Mehta offers a different perspective on adoptive cell therapy, with a look at natural killer (NK) cell therapy. NK cells are unique in that they are promptly activated without prior sensitization, and their responsiveness is regulated by a balance between an array of inhibitory and activating receptors, without the need for antigen specificity. Dr. Mehta reviews NK cell therapy in both the autologous and the allogeneic setting in combination with hematopoietic stem cell transplantation.

Multiple myeloma creates an immunosuppressive milieu in tumor sites within the bone marrow, presenting therapeutic opportunities via the disruption of immunosuppression. Dr. Hideto Tamura reviews the interplay between myeloma cells and immune cells, and strategies for reversing the immunosuppressive environment.

How is immunotherapy for hematological malignancies likely to advance in the near future? Engineered T cell therapy will expand its territory into lymphoid and possibly myeloid malignancies. As targeted therapy and immunotherapy are complementary, and several targeted drugs have immune-enhancing effects [5-7], combinations of targeted therapy and immunotherapy will no doubt be tested for synergistic effects. A succession of innovative new therapies will certainly continue to change the therapeutic landscape for hematological malignancies. 


\section{References}

1. Ansell SM, Lesokhin AM, Borrello I, Halwani A, Scott EC, Gutierrez M, et al. PD-1 blockade with nivolumab in relapsed or refractory hodgkin's lymphoma. N Engl J Med. 2015;372:311-9.

2. Chen R, Zinzani PL, Fanale MA, Armand P, Johnson NA, Brice $\mathrm{P}$, et al. Phase II study of the efficacy and safety of pembrolizumab for relapsed/refractory classic hodgkin lymphoma. J Clin Oncol. 2017;35:2125-32.

3. Dave SS, Wright G, Tan B, Rosenwald A, Gascoyne RD, Chan WC, et al. Prediction of survival in follicular lymphoma based on molecular features of tumor-infiltrating immune cells. N Engl J Med. 2004;351:2159-69.

4. Lenz G, Wright G, Dave SS, Xiao W, Powell J, Zhao H, et al. Stromal gene signatures in large-B-cell lymphomas. N Engl J Med. 2008;359:2313-23.
5. Mustjoki S, Ekblom M, Arstila TP, Dybedal I, Epling-Burnette PK, Guilhot F, et al. Clonal expansion of T/NK-cells during tyrosine kinase inhibitor dasatinib therapy. Leukemia. 2009;23:1398-405.

6. Dubovsky JA, Beckwith KA, Natarajan G, Woyach JA, Jaglowski $\mathrm{S}$, Zhong Y, et al. Ibrutinib is an irreversible molecular inhibitor of ITK driving a Th1-selective pressure in T lymphocytes. Blood. 2013;122:2539-49.

7. Krönke J, Udeshi ND, Narla A, Grauman P, Hurst SN, McConkey $\mathrm{M}$, et al. Lenalidomide causes selective degradation of IKZF1 and IKZF3 in multiple myeloma cells. Science. 2014;343:301-5. 